\title{
Analisis Konsep Abrahamic Faiths dan Kaitannya dengan Pluralisme Agama
}

\author{
Analysis of the Concept of Abrahamic Faiths and Its Relation \\ to Religious Pluralism
}

SUHAIDA SHAHARUD-DIN* \& KHADIJAH MOHD KHAMBALI @ HAMBALI ${ }^{1}$

\begin{abstract}
Abrahamic Faiths often referred to Judaism, Christianity and Islam that put this categorization based on a number of features common to all three religions in the same cluster. Terminology of Abrahamic Faiths within the contemporary real-world comparative religion has been manipulated by leaders to strengthen the concept of religious pluralism is not only related to the Abrahamic Faiths, but also related to wad'i religions on the basis of prophetic chronology of Abraham. In reality, the position of Abrahamic Faiths has evolved appropriate real philosophical doctrines that every reality is much different. Therefore, this study will reveal and analyze the concept of Abrahamic Faiths in the context of religious studies to provide clarification on the ambiguity arising out of the equation. In addition to analyzing relationship between religious pluralism that makes the concept of Abrahamic Faiths seen as one of the themes of religious generalizations on the basis of prophetic chronology equation as the way for religious tolerance.
\end{abstract}

Keywords: Abrahamic Faiths, religious pluralism, Judaism, Christianity.

Abrahamic Faiths merupakan dua perkataan berasal daripada bahasa Inggeris Abrahamic dan Faiths. Abrahamic berkaitan dengan Abraham atau Ibrahim iaitu bapa kepada segala Nabi. Rata-rata pengkaji Muslim dan Barat mengiktiraf agama Yahudi, Kristian dan Islam berasal daripada Nabi Ibrahim. Ini diperkukuhkan lagi dengan kisah-kisah historis dalam kitab suci masing-masing. Perkataan Faiths merupakan perkataan bahasa Inggeris yang berasal dari Latin iaitu fidere yang bermaksud untuk mempercayai (to trust) (Reese 1980: 166). Ianya boleh diertikan sebagai suatu kepercayaan yang mana ianya melampaui bukti yang wujud. Begitu juga Faiths menurut Kamus Oxford, berkait dengan soal hati di mana ianya terhubungkait dengan keimanan penganut yang dapat memberi komitmen dan dapat menerima tuntuntan agama (Bowker 1997: 334). Faiths lebih tepat jika dimaksudkan dengan keyakinan, kepercayaan terhadap tuntutan agama. Oleh yang demikian, kepercayaan dan keyakinan itu juga merupakan agama yang hanya boleh diterima dari Tuhan sebagai hadiah dan rahmat dan menjadi cara di mana terbentuknya sesebuah kepercayaan. Diperhalusi makna faiths menurut Oxford Dictionary mempunyai tiga makna yang agak serupa berkenaan perkataan faiths yang berasal dari perkataan Latin iaitu: 1 . Kepercayaan atau keyakinan yang lengkap terhadap seseorang atau sesuatu (Complete trust or confidence in someone or somethings.); 2. Kepercayaan yang kukuh terhadap agama

${ }^{1}$ Suhaida Shaharud-din*(Corresponding author), Ph.D. Candidate at Academy of Islamic Studies, University of Malaya, 50603 Kuala Lumpur, Malaysia; Khadijah Mohd Khambali @ Hambali, Ph.D. Assoc. Prof. at Academy of Islamic Studies, University of Malaya, 50603 Kuala Lumpur, Malaysia. Email: ijamh@um.edu.my. 
(Strong belief in religion, dan; 3. Sebuah sistem kepercayaan agama (A system of religious belief).

Apabila perkataan Faiths dirujuk kepada Abraham, ianya menjadi lebih khusus yang mana tertumpu kepada sebuah sistem kepercayaan agama Abraham (Ibrahim). Perkataan faiths digunakan berikutan kepercayaan dan keimanan Abraham terhadap Tuhan yang satu di dalam agama masing-masing. Hal ini terbukti apabila setiap agama meletakkan status Nabi Ibrahim berbeza-beza setiap agama berdasarkan kepada Faiths (kepercayaan/iman) kepada PenciptanNya. Agama Yahudi meletakkan kedudukan Abraham sebagai Father of Many Nation berikutan keimanan dan kesabaran beliau menghadapi tekanan ketiadaan zuriat dan Tuhan telah menjanjikan beliau bapa yang mempunyai banyak keturunan seperti yang termaktub dalam Genesis (17:5). Rentetan daripada itu, agama Kristian telah meletakkan beliau sebagai Father of Faiths di dalam Roman (3:27) dan Roman (4:25) yang dilihat memberi suatu contoh teladan ke atas penyaliban Jesus di tiang salib berikutan keimanan dan kesabaran beliau mengkorbankan anaknya, Isaac. Manakala agama Islam meletakkan Nabi Ibrahim sebagai Khalilullah berikutan perjalanan dakwah baginda yang mengharungi pelbagai rintangan bagi menuju agama Hanif dengan tugas dakwahnya kepada tiga golongan utama pada ketika itu iaitu penyembah berhala, penyembah bintang, bulan dan matahari serta penyembah raja iaitu Raja Namrud sebagai tanda kasih sayang Allah kepada Nabi Ibrahim di atas segala bentuk pengorbanan dan keimanan dalam menegakkan agama Hanif.

Menurut al-Quran agama Ibrahim disebut sebagai Millat Ibrahim (Baqarah 2:120). Terdapat sebanyak 15 surah yang berlainan di dalam al-Quran yang menggunakan perkataan millat yang ke semuanya ditujukan secara langsung mahupun tidak langsung kepada kepercayaan agama Nabi Ibrahim. Kepercayaan atau iman Nabi Ibrahim di dalam alQuran dirujuk kepada perkataan Hanif yang membawa maksud lurus. Justeru millat Ibrahim yang bercirikan Hanif bermaksud agama yang lurus, suci dan benar. Islam menyakini bahawa agama Yahudi dan Kristian yang dibawa oleh Nabi Musa dan Nabi Isa juga merupakan agama Hanif yang menyembah Tuhan yang Esa sebelum ianya diselewengkan. Namun Islam telah menolak kebenaran agama Yahudi dan Kristian berikutan penyelewengan yang telah dilakukan. Istilah Abrahamic Faiths muncul seiring kemunculan ilmu perbandingan agama apabila berlakunya inter-faiths dialog di antara ketiga-tiga agama besar dunia ini. Pertemuan pertama yang diadakan pada zaman khalifah Damsyik di Baghdad dan Cordova di antara ketiga-tiga agama Yahudi, Kristian dan Islam sehingga melahirkan ilmu al-Milal wa Nihal lanjutan daripada itu, pertemuan sekali lagi pada tahun 1974 yang dinamakan The Muslim-Jewish-Christian Conference (MJCC) telah melahirkan dan mewujudkan perkataan Abrahamic Faiths yang bertujuan menjadi suatu platform dan jambatan kepada agama Yahudi, Kristian dan Islam dalam memahami dan pengaplikasian komunikasi dengan satu sama lain atas hal-hal agama untuk menjana harmoni dan toleransi.

\section{Definisi Abrahamic Faiths}

Abrahamic Faiths merupakan istilah bahasa Inggeris yang sering digunakan untuk menamakan dan mengkelompokkan agama Yahudi, Kristian dan juga Islam sebagai agama bersusurgalur daripada nabi Ibrahim. Tuntasnya, ketiga-tiga agama ini sering dirujuk dan disebut sebagai Abrahamic Faiths iaitu agama-agama Nabi Ibrahim. Menurut Jerald F. Dicks (2006) ketiga-tiga agama ini digelar Abrahamic Faiths kerana ketiga-tiga agama tersebut bersusur galur daripada keturunan Nabi Ibrahim. Beliau juga menambah bahawa lahirnya perkataan Abrahamic Faiths itu bukan sahaja kerana ianya bersusur galur daripada 
keturunan yang sama bahkan ianya seiring dengan perkembangan Ilmu Perbandingan Agama khususnya dalam topik pengkategorian agama-agama dunia yang menonjolkan agama-agama tersebut sering dikategorikan dalam kelompok yang sama. Sebagai contoh yang telah dikemukakan oleh beliau ialah apabila timbul pengkategorian antara agama monotisme dan politisme, antara agama kenabian dan bukan kenabian serta agama di Timur Tengah dan Timur. Jelasnya ketiga-tiga agama ini merupakan agama monotisme, kenabian dan Timur Tengah. Justeru agama ini sering dikategorikan dalam kelompok yang sama. Ini telah memangkinkan kemunculan istilah Abrahamic Faiths dalam menamakan ketiga-tiga agama tersebut.

Menurut Valkenberg (2006), nama Abrahamic Faiths ini diambil berikutan susur galur kenabian yang dipercayai oleh ketiga-tiga agama tersebut melalui metode historis mahupun kitab suci masing-masing. Perkataan Abrahamic Faiths juga sering digunakan untuk menjadi terma dalam dialog yang diadakan oleh tokoh-tokoh Ilmu Perbandingan Agama; seperti dialog di antara Yahudi, Kristian dan Islam.

\section{Status Abrahamic Faiths dari Perspektif Kajian Agama}

Agama Yahudi, Kristian dan Islam telah diiktiraf sebagai Abrahamic Faiths iaitu agamaagama nabi Ibrahim oleh kebanyakan tokoh sarjana Perbandingan Agama. Pengiktirafan ini berasaskan bahawa ketiga-tiga agama ini mempunyai persamaan walaupun diakui mempunyai perbezaan dari segi pegangan dan doktrin masing-masing. Namun ciri dan persamaan yang diberikan dalam pengiktirafan ini tidak begitu jelas untuk membuktikan ketiga-tiga agama ini diiktiraf sebagai Abrahamic Faiths. Pun begitu, beberapa ciri persamaan Abrahamic Faiths telah dibahaskan menurut perspektif Kajian Agama.

Beberapa ciri yang meletakkan pengiktirafan kepada ketiga-tiga agama tersebut sehingga diklasifikasikan sebagai Abrahamic Faiths, iaitu: 1. Ketiga-tiga agama tersebut merupakan agama yang bersusur galur daripada Nabi Ibrahim (Valkenberg 2006); 2. Ketiga-tiga agama tersebut merupakan agama monotisme iaitu menyembah tuhan yang Satu (Chittister 2006), dan; 3. Ketiga-tiga agama tersebut berasal daripada agama semitik (Dicks 2006).

\section{Agama Bersusur galur Nabi Ibrahim}

Ciri yang pertama memperlihatkan bahawa ketiga-tiga agama besar dunia ini berkongsi personaliti yang sama iaitu Nabi Ibrahim (Dicks 2006). Ketiga-tiganya juga mempercayai kewujudan dan pengiktirafan Nabi Ibrahim sebagai nabi dan rasul yang diutuskan kepada kaumnya dan persamaan ini dilihat dari sudut nabi Ibrahim sebagai bapa kepada keturunan Bani Israel dan Arab (Cohen 2010). Namun persamaan ini hanyalah tertumpu kepada susurgalur agama yang dimulai dengan agama Nabi Ibrahim. Bahkan perbezaan yang ketara di antara ketiga-tiganya nampak jelas apabila sejarah dan konotasi cerita yang berbeza di dalam kitab suci masing-masing. Hal ini kerana agama Yahudi menyakini bahawa Nabi Ibrahim sebagai bapa kepada bangsa Bani Israel yang bersusurgalur daripada Isaac (Nabi Ishak). Manakala agama Kristian juga menyakini bahawa mereka juga berketurunan Nabi Ibrahim berdasarkan Romans (4:16) "Father all of us".

Islam turut menyakini bahawa Nabi Ibrahim membawa agama Hanif yang turut didokong dari zaman Nabi Adam a.s sehingga Nabi Muhammad s.a.w. Islam menyakini bahawa susurgalur tersebut dari Nabi Ismail dan ibunya berbangsa Arab merupakan susurgalur yang terbentuk sehingga kepada Nabi Muhammad s.a.w. Apatah lagi Islam tidak menolak kenabian nabi-nabi terdahulu dan menyakini bahawa agama Yahudi dan Nasrani 
merupakan Islam yang benar iaitu agama yang menyeru kepada pentauhidan Allah seperti agama Islam sebelum ianya diselewengkan. Jelas bahawa ketiga-tiga agama besar dunia ini menyakini akan susurgalur keturunan berasal daripada nabi Ibrahim walaupun ketigatiganya mempunyai sejarah yang berbeza menurut kitab suci masing-masing dan kajian para sejarawan. Kisah historis ketiga-tiga agama turut dinyatakan di dalam kitab suci masing-masing dengan konotasi yang berbeza. Persamaan ketara yang dapat disimpulkan ialah ketiga-tiga agama tersebut mempercayai bahawa Nabi Ibrahim merupakan bapa kepada bangsa Israel dan Arab. Justeru, ketiga-tiga agama tersebut mempunyai pertalian yang kukuh antara satu sama lain.

\section{Agama Monotisme dan Agama Berasal Agama Semitik}

Pengiktirafan ini juga berkait rapat dengan ciri monotisme yang dibawa dan diajar oleh Nabi Ibrahim. Mono diambil daripada perkataan Greek iaitu monos. Perkataan monos bukan hanya bermaksud 'tuhan yang satu' bahkan 'hanya satu-satunya' (Valkenberg 2006: 60). Istilah ini lazimnya digunakan oleh agama yang berfahaman monotisme radikal. Tuntasnya, monotisme bermaksud kepercayaan kepada tuhan yang satu yang mencipta dan mentadbir alam. Ketiga-tiga agama tersebut berkongsi konsep monotisme. Pun begitu, konsep monotisme yang dianuti oleh agama tersebut adalah berbeza bersesuaian dengan falsafah dan tuntutan agama masing-masing. Ini juga bertepatan dengan konsep istilah monotisme yang telah diklasifikasikan kepada pelbagai bentuk monotisme dan antaranya monotisme radikal atau rigid (Valkenberg 2006) dan monotisme tunggal (Wyschogord 1995). Menurut sarjana Barat, monotisme radikal lebih menjurus kepada agama Yahudi dan Islam untuk mempertahankan pemikiran dan pegangan politiesm iaitu pegangan banyak tuhan. Manakala Wyschogord (1995) menegaskan bahawa monotisme tunggal atau lebih dikenali sebagai monotisme tertinggi lebih menjurus kepada agama Islam sahaja bersesuaian dengan status keyakinan Islam sebagai agama tauhid (Samsudin 2012: 31). Konsep monotisme amat berkait rapat dengan ajaran nabi Ibrahim yang menyembah tuhan yang satu. Cardinal Sergio Pignedoli dalam ucapannya menyatakan bahawa ketiga-tiga agama majoriti ini yang merujuk kepada Yahudi, Kristian dan Islam menyakini dan mempercayai kenabian Nabi Ibrahim yang menekankan agama monotisme telah meletakkan ketiga-tiga agama tersebut turut diiktiraf sebagai agama nabi Ibrahim dengan rujukan persamaan monotisme yang umumnya menegaskan kepercayaan tuhan yang satu, tuhan yang mencipta alam dan tuhan yang mengutuskan nabi kepada umat manusia. Beliau menegaskan lagi bahawa realitinya ketiga-tiga agama ini berkongsi tuhan yang sama iaitu tuhan yang melantik nabi Ibrahim dan mengutuskan agama Nabi Ibrahim.

Bagi Semitik pula, ia telah turut diletakkan sebagai garis panduan penentuan persamaan di antara ketiga-tiga agama besar dunia ini dan istilah Semitik itu telah dinamakan oleh A.L Schoezler pada tahun 1781 di dalam J.G. Eichhorn's Repertorium fuer Biblishe und morgenlaendische Literatur (Lipinski 2001: 21). Semitik merupakan bahasa, tatacara hidup yang menjadi identiti kepada masyarakat Shem. Perkataan Sem adalah berasal daripada Shem yang terdapat di dalam Bible dan beliau merupakan anak keturunan Nabi Noh (Genesis 6:10). Bahasa pertuturan bangsa Shem yang merangkumi bahasa Arab, Aramaic, Hebrew, Akkadian (Lipinski 2001, Amstrong, K. 1993: 6), Ethiopic, Phoenician (http://en.wikipedia.org/wiki/Shem) yang kini lebih dikenali sebagai Afro-Asiatic telah dirujuk sebagai bahasa Semitik. Ini telah meletakkan bahasa Semitik sebagai bahasa pertuturan dan perantaraan komunikasi kepada agama Yahudi, Kristian dan Islam. Atas asas sinonimnya bahasa pertuturan dan komunikasi antara mereka ini juga; agama-agama tersebut dikategorikan sebagai agama Semitik. Apatah lagi menurut pensejarahan agama 
Yahudi dan Kristian yang dinukilkan daripada Bible (Genesis 10:22), Abraham merupakan keturunan Noah yang bersusur galur kepada Arphaxad iaitu anak kepada Shem (1 Chronicles 1:17) dan ini bererti Abraham adalah seorang Semit. Ini mengukuhkan lagi kedudukan agama-agama Nabi Ibrahim disebut dan dikenali sebagai agama Semitik. Ketigatiga ciri yang dilihat daripada perspektif kajian agama merupakan ciri dan konsep Abrahamic Faiths yang berdiri dengan sendirinya tanpa terkait dengan faham pluralisme agama. Kelangsungan daripada ciri persamaan ini telah membentuk keterikatan dengan faham pluralisme agama yang dilihat mewarnai dunia perbandingan agama.

\section{Keterkaitan Pluralisme Agama Bertemakan Abrahamic Faiths}

Pluralisme agama secara langsung telah mengikat Abrahamic Faiths yang pada asalnya berada di luar lingkaran Pluralisme agama. Pembinaan asal perkataan Abrahamic Faiths bertujuan membina keharmonian yang dilihat dari sisi memahami dan pengaplikasian komunikasi antara satu sama lain atas hal-hal berkaitan keagamaan namun kesempatan ini telah diambil oleh tokoh-tokoh pluralisme agama sehingga meletakkan kesamaan kedudukan dan taraf agama Yahudi, Kristian dan Islam di atas dua ciri persamaan, iaitu Tuhan yang sama iaitu tuhan Abraham (Nabi Ibrahim a.s). (Nasr 2007: 43; al-Faruqi 1995: 161), serta Tuhan yang satu iaitu konsep monotisme (McGrath 2009: 1).

\section{Tuhan Yang Sama iaitu Tuhan Ibrahim (God of Abraham)}

Tokoh-tokoh pluralisme agama khususnya Muslim seperti Hashim Kamali banyak menggunakan ciri Tuhan yang sama (God of Abraham) dan dikukuhkan lagi dengan alQuran dari surah al-Baqarah ayat 136 dan 285:

Katakanlah (Wahai orang-orang Yang beriman): "Kami beriman kepada Allah, dan kepada apa Yang diturunkan kepada Kami (Al-Quran), dan kepada apa Yang diturunkan kepada Nabi Ibrahim dan Nabi Ismail dan Nabi Ishak dan Nabi Yaakub serta anak-anaknya, dan juga kepada apa Yang diberikan kepada Nabi Musa (Taurat) dan Nabi Isa (Injil), dan kepada apa Yang diberikan kepada Nabi-nabi dari Tuhan mereka; Kami tidak membezabezakan antara seseorang dari mereka (sebagaimana Yang kamu - Yahudi dan Nasrani - membeza-bezakannya); dan Kami semua adalah Islam (berserah diri, tunduk taat) kepada Allah semata-mata".

Walaupun ramai tokoh sarjana Barat yang bersependapat bahawa ketiga-tiga agama besar dunia ini mempunyai pertalian yang erat dari segi sejarah kenabian, kepercayaan, dan penurunan kitab suci namun hal ini tidak bermakna Islam menerima persamaan ini secara total sehingga menyamakan taraf ketiga-tiga di bawah tema Abrahamic Faiths. Ternyata secara jelasnya perbezaan kisah historis, kepercayaan mahupun penurunan kitab suci sangat berbeza di antara agama Yahudi, Kristian dan Islam. Malah Islam tidak menganggap Tuhan Allah yang disembah sama dengan agama Yahudi dan Kristian berdasarkan zat dan sifat Tuhan yang diyakini setiap penganut Muslim (Khadijah 2010: 22). Berbeza hal keadaan agama Yahudi dan Kristian mengenai zat dan sifat Tuhan yang digambarkan mempunyai anak. Bagi golongan pluralisme agama seperti Seyyed Hossein Nasr beliau mendakwa bahawa kepelbagaian agama yang berbeza diwujudkan oleh Allah merupakan suatu pendedahan kepada nama dan sifat ketuhanan yang berbeza setiap agama memberi penekanan kepada aspek teologi. Jelas bahawa Nasr (2007) menyakini bahawa Tuhan yang 
diyakini oleh agama Islam iaitu Allah merupakan Tuhan yang sama di dalam agama Yahudi dan Kristian yang hanya berbeza pada nama dan sifat sahaja. Pendapat Seyyed Hossein Nasr banyak menerima pandangan Schoun (1984) yang menjelaskan bahawa satu agama berbeza dengan agama lain dalam level eksotrik, tetapi relatif sama dalam level eksotriknya. Oleh kerana itu ada istilah "Satu Tuhan Banyak Jalan".

\section{Tuhan Yang Satu dan Konsep Monotisme}

Rentetan daripada berkongsi Tuhan sama yang dipercayai dan diyakini oleh kebanyakan tokoh pluralisme agama, konsep monotisme pula menyusuli keterkaitan terhadap pluralisme agama. Kepercayaan asas yang dipercayai oleh Yahudi, Kristian dan Islam mempercayai bahawa Tuhan telah membuat perjanjian dengan Abraham (Nabi Ibrahim) untuk menyakini dan mengimani kepercayaan kepada Tuhan yang satu. McGrath (2009) dan Lemaire (2007) menerangkan konsep monotisme telah diyakini bermula sejak zaman nabi Ibrahim menyembah Tuhan YHWH dan juga permulaan agama Kristian menyembah Tuhan yang satu sebelum pembentukan Doktrin Triniti. Ditambah pula oleh tokoh-tokoh pluralisme seperti Amstrong, K. (1993) mengakui ketiga-tiga agama tersebut merupakan agama monotisme. Selain itu, Aslan (1994) di dalam bukunya menyatakan bahawa John Hick bersetuju dengan pendapat yang menyatakan bahawa ketiga-tiga agama tersebut merupakan agama monotisme dengan dua fungsi Tuhan iaitu Universality (universal) dan Particularity (Khusus). Tuhan itu mempunyai fungsi yang sama sebagai pencipta, pentadbir alam dan yang menurunkan kenabian. Maka dia juga mempunyai fungsi khusus yang tersendiri di dalam agama Yahudi, Kristian dan Islam. Digelar sebagai monotisme berikutan kepercayaan kepada Tuhan yang satu mencipta seluruh alam sejagat raya di langit dan di bumi. Keterkaitan Abrahamic Faiths dengan faham pluralisme agama telah memberi suatu kekaburan bahawa semua agama sama benar disebabkan bersusurgalur daripada Abraham (Nabi Ibrahim) dan mendakwa bahawa memiliki Tuhan yang sama seperti Tuhan Nabi Ibrahim. Ciri umum Abrahamic Faiths dan keterkaitan dengan faham pluralisme agama telah mencetuskan salah faham pluralisme agama dengan membawa penyamarataan agama dengan berkonsepkan toleransi beragama. Walhal ketiga-tiga agama besar dunia ini nyata berlainan dari segi memahami konsep Tuhan dan konsep monotisme yang didukung oleh setiap agama selari dan sejajar dengan tuntutan falsafah dan ajaran agama masing-masing. Islam sentiasa berpegang pada konsep Tawhid Allah yang Esa dan tidak ada penyengutuan terhadapNya. Kebersamaan yang diserlahkan oleh setiap agama adalah kesalingan hubungan antara umat beragama agar keharmonian dan keamanan hidup sedia wujud akan terus terpelihara dan setiap agama memahami bahawa agama adalah identiti istimewa setiap individu penganut. Jika bukan begitu, pastinya tidak wujud istilah penganut Yahudi, Kristian dan Muslim yang sekaligus menyerlahkan bahawa keyakinan individu penganut tersebut adalah berbeza walaupun asasnya dan asalnya keturunan nabi yang membawa agama-agama tersebut bersusrgalurkan kepada nabi Ibrahim a.s. Namun pengiktirafan yang diberikan kepada Islam sebagai agama yang lengkap dan terakhir telah meletakkan kebersamaan ciri umum yang dikongsi bersama perlu dirinci dan direncamkan agar maksud pluralisme itu sejajar dengan apa yang ditegaskan oleh Islam.

\section{References}

Aslan, A. 1994. Religious Pluralism In Christian and Islamic Philosophy: The Thought of John Hick and Seyyed Hossein Nasr. United Kingdom: Carzon Press Ltd. 
Al-Faruqi, I. R. 1995. Trialogue of The Abrahamic Faiths. United Stated of America: Amana Publications.

Amstrong, K. 1993. History of God: The 4,000 Year Quest of Judaism, Christianity and Islam. New York: Ballantine Books.

Bible of New Testament and Old Testament. 2011. United Kingdom: Grand Rapids.

Bowker, J. (e.d.). 1997.The Oxford Dictionary of World Religions. New York: Oxford University Press.

Chittister, J., Chisti, M.S.S., Arthur Waskow, A., Armstrong, K. 2006. The Tent of Abraham: Stories of Hope and Peace For Jews, Christians and Muslims. Britain: Beacon Compress.

Cohen, A. M. 2010. The Monotheistic Religions: Judaism, Christianity and Islam. United Stated of America: Mason Crest Publishers.

Dick, J. F. 2006. Abrahamic Faiths:Titik Temu dan Titik Seteru Antara Islam, Kristian dan Yahudi, Astuti S. I. Trj. The Abrahamic Faiths: Judaism, Christianity and Islam Similarities and Contrasts. t.tp.: PT Serambi Ilmu Semesta.

Hick, J. 2006. Pluralisme keagamaan dalam Islam. Radhi, A.M. Trj. Islam dan Pluralisme. Kuala Lumpur: Pusat Siswazah Timur Tengah.

Hick J. 1985. Problems of Religious Pluralism. New York: St. Martin's Press.

Lemaire, A. 2007. The Birth of Monotheism: the Rise and Disappearance of Yahwism. Washington: Biblical Archaeology Society.

Lipinski, E. 2001 Semitic Languanges Outline of A Comprerative Grammar. (2nd ed.). Belgium: Peters Publishers and Department of Oriental Studies.

Khadijah Mohd Khambali@Hambali. 2010. Analisis Kalimah Allah Menurut Perspektif Ahl Sunnah Wa Jamaah. Kertas Kerja Seminar Pemikiran Islam Peringkat Kebangsaan II di Universiti Malaya, 20-22 July.

McGrath, J. 2009. The Only True God: Early Christian Monotheism in Its Jewish Context. Chicago: University of Illinois Press.

Nasr, S. H. 2007. The Essential Seyyed Hossain Nasr. Indiana: World Wisdom. http://books.google.com.my/books?id=0YQhoPEih04C\&pg=PA43\&lpg=PA43\&dq=s eyyed+hossein+nasr+same+god\&source=bl\&ots=4b4RySp5BM\&sig=5UzkJfQFvNjs3 fs-BBJct7cgl4M diaskes pada 30 September 2012.

Reese, W. L. 1980. Dictionary of Philoshopy and Religion. United Stated of America: Humanities Press INC.

Samsudin Abdul Hamid. 2012. Konsep Monoteisme dalam Aliran Saivisme: Analisis Menurut Perspektif Islam. Disertasi Sarjana Usuluddin. Jabatan Akidah dan Pemikiran Islam, Akademi Pengajian Islam. Universiti Malaya.

Schoun, F. 1984. The Transcendent Unity of Religion. United Sated of America: Theosophical Publications House.

Swidler, L. 2007. Freedom of Religion and Dialogue: Moving Globalization From 'Destruction' To 'Construction. Dlm. Nathan K.S.(Ed.) Religious Pluralism in Democratic Societies: Challenges and Prospects For Southeast Asia, Europe and The United States in The New Millenium. Singapura: Konkrad-Adenauer-Stiftung.

Valkenberg, P. 2006. Sharing The Light On The Way To God: Muslim-Christian Dialogue and Theology in The Context of Abrahamic Partnership. Amsterdam: Rodopi B.V.

Wyschogord, M. 1995. Islam and Christianity in The Perspective of Judaism. Dlm. al-Faruqi, I.R. (ed.). Trialogue of The Abrahamic Faiths. United States: Amana Publications. 